\title{
Teatro entre elas: o teatro em comunidade como partilha do sensível
}

Vânia Pereira Silvério

Submetido em: 14/04/2020

Aprovado em: 08/06/2020

DOI: $10.5965 / 2358092521232020162$

1 Mestranda (2018-2020) no Programa de Pós-Graduação em Artes (EBA-UFMG) e professora de Teatro no ensino regular em rede de ensino particular de Belo Horizonte. E-mail: vaninhapsilverio@hotmail.com 


\section{RESUMO}

Esse artigo salienta a pesquisa, desenvolvida em processo de Mestrado, que refletiu sobre o trabalho realizado no Grupo Teatro Entre Elas, residente na Associação Cultural Casa do Beco, no campo do Teatro em Comunidades, a partir dos apontamentos levantados por Nogueira (2008), entrelaçados à noção de "partilha do sensível", postulada por Rancière (2009). Pensar o Teatro Entre Elas no campo do Teatro em Comunidades e este como uma partilha do sensível é uma reflexão que abrange o fazer artístico, e a dimensão política que atravessa a existência desse grupo de mulheres. Para tanto, narro o trabalho desenvolvido no Grupo, destacando a remontagem da peça "Quando eu vim para um Belo Horizonte", e teço reflexões sobre sua relação com o campo do Teatro em Comunidades e este como uma partilha do sensível. Trata-se, portanto, de uma narrativa que buscou contribuir para a discussão de práticas que acontecem em contextos comunitários e que fazem emergir vozes e corpos antes silenciados e ignorados.

Palavras-chave: teatro em comunidades, partilha do sensível, arte, vida, política.

\section{ABSTRACT}

This article ensure the research, developed in master's degree in progress, that had reflected about the work presented at the group "Teatro Entre Elas", taking place at Associação Cultural Casa do Beco, (House of the Alley Cultural Association), in the field of Theaters in Communities, according of notes raised by Nogueira (2008), intertwined by a notion of "sensitive sharing" postulated by Rancière (2009). To think about the group "Teatro Entre Elas" in the theater department in the communities such as a sensitive sharing is a reflection that comprises artistry and political dimensions, crossing 
this women's group existence. Therefore, I relate the work developed at the Group, highlighting the remembrances of the play "Quando eu vim para um Belo Horizonte" (When I've came to a beautiful horizon), and I weave reflections towards its relation with the field of Theater in Communities and that as a sensitive sharing. It is however, from a narrative that sought to contribute for a discussion of practices that occur in communitarian contexts, and create an emersion of voices and bodies until then silenced and ignored.

Keywords: theaters in communities, sensitive sharing, art, life, politics.

\section{AO ENCONTRO DO GRUPO TEATRO ENTRE ELAS}

Em processo de pesquisa de Mestrado, desenvolvida no âmbito do PPGArtes/EBA/UFMG², narrei um encontro, prático e reflexivo, com o Grupo Teatro Entre Elas, um grupo de mulheres que se unem em prol do fazer teatral, abrigadas pela Casa do $\mathrm{Beco}^{3}$, sendo este um ponto de cultura localizado aos pés do Morro do Papagaio/ $\mathrm{BH}^{4}$.

Aproximar deste grupo e desta temática de pesquisa é uma inquietação que se justifica por um percurso de vida e arte. Em trajetória acadêmica, tive a oportunidade de trabalhar com gru-

2 Programa de Pós Graduação em Artes da Escola de Belas Artes - Universidade Federal de Minas Gerais.

3 Casa do Beco está localizada a Av. Arthur Bernardes, 3876 - Santa Lúcia, Belo Horizonte - MG. Saiba mais em http://www.casadobeco.org.br/. Acesso em Mar. 2020.

40 Morro do Papagaio pertence ao Aglomerado Santa Lúcia na região centro-sul da cidade de Belo Horizonte, em Minas Gerais, sendo formado por quatro vilas: Vila Estrela, Vila Santa Rita de Cássia, Vila São Bento e Vila Aglomerado Santa Lúcia. 
pos de idosos em projeto de extensão universitária: trabalho guiado pelo uso de memórias, tendo em seu percurso realizado a montagem de espetáculos teatrais.

Em trabalho monográfico para concluir o curso de Licenciatura em Teatro/UFMG, optei em trabalhar com grupo de idosos, utilizando também de memórias como mote para expressão cênica, fazendo uso do Diário de Bordo (BARBIER, 2007), método potente de investigação do trabalho em campo, em exercício de escrita e reflexão. Dessa forma, este se fez presente também no processo de pesquisa de Mestrado.

De tal forma, opto por transcrever alguns fragmentos do meu diário ao longo desta comunicação, entendendo sua marca de um registro fresco de uma experiência, imbuído de impressões e sentimentos momentâneos, como forma de exemplificação, de imagens produzidas pela descrição, e como uma maneira de aproximação do leitor com a experiência vivida.

Em processo de pesquisa e imersão no campo de estudo, foram realizadas entrevistas, com seis integrantes do grupo e os professores/diretores Nil Cézar ${ }^{5}$ e Liliane Alves ${ }^{6}$, que buscou ouvir narrativas que compreendessem os começos do trabalho e a formação atual do Grupo Teatro Entre Elas. As entrevistas foram semiestruturadas, partindo de algumas perguntas traçadas que buscavam entender o percurso histórico e os desejos de vida e arte e, assim, íamos construindo um diálogo. Pequenos trechos dessas entrevistas surgirão ao longo do texto, enfatizando suas vozes e suas experiências. Penso que seja indispensável deixá-las emergirem nesta reflexão, que busca salientar a importância desse espaço em que suas vozes possam ser ouvidas e seus corpos serem vistos.

No período de abril de 2018 a junho de 2019, estive presente nos encontros do Grupo, mediados pela professora Liliane. Nesse percurso, busquei ficar ativa e atenta aos seus processos

5 Nil César é fundador e gestor da Casa do Beco. É ator, diretor e dramaturgo.

6 Liliane Alves é formada em Letras com Mestrado em Teoria da Literatura na UFMG. É terapeuta holística, cantora e atriz. É professora, diretora e dramaturga do Grupo Teatro Entre Elas. 
e rotinas. Fui, aos poucos, compreendendo as características que se apresentaram potentes para o processo de reflexão: o contexto comunitário envolvido, o trabalho criativo pautado na improvisação e criação coletiva e a dimensão política que perpassava esse fazer.

\section{PERCURSO ARTÍSTICO E A REMONTAGEM QUANDO EU VIM PARA UM BELO HORIZON- TE (2019)}

Quinze mulheres, destas, quatro não são moradoras do Morro do Papagaio. É o encontro de teatro que une Adriana Borges, Graça Dias, Du Carmo Fernandes, Milta de Oliveira, Cruzelina Conceição, Maurina Eugênia, Susete Souza, Rosa Santos, Júnia Leonel, Ana Oliveira, Rita de Almeida, Adeguimar de Jesus, Dionísia Marques, Maria das Mercês e Maria Geralda de Paula7, duas vezes por semana, com dois espetáculos em repertório. Destas quinze, quatro estão escrevendo esta história desde o início. Em 2017, houve uma integração com as mulheres que estavam frequentando a oficina $O$ Afeto na melhor idade, parceria da Casa do Beco com o posto de saúde local, configurando o elenco atual do Grupo Teatro Entre Elas.

Todo alicerce dessa construção está atrelado à figura de Nil, que aos 11 anos descobriu o teatro, se encantou pela arte e aos 20 anos fundou o que seria mais tarde o Grupo do Beco, que daria origem à Associação Cultural Casa do Beco. E é nesse emaranhado que nasceu o trabalho teatral com um grupo de mulheres.

Eram os idos de 2011 quando uma parceria da Casa do Beco com o CRAS $^{8}$ Santa Rita de Cássia reverberou um desejo - advindo dos tempos da montagem do espetáculo Bendita: a

7 Todas as integrantes, assim como os professores/diretores autorizaram o uso de seus nomes reais.

8 CRAS - Centro de Referência de Assistência Social. 
voz entre as mulheres ${ }^{9}$, realizado pelo Grupo do Beco -: trabalhar com mulheres, moradoras do próprio morro, a linguagem teatral para que pudessem, agora, elas mesmas, narrarem suas histórias em cena.

Independente de tempos de jornada no grupo, as histórias de vida se encontram e reencontram nas lutas diárias pela sobrevivência, na aridez dos solos percorridos, nos desafios enfrentados durante a vida. Com idades variando de 40 a 82 anos, um espaço de arte e afeto é intensificado no teatro entre elas, ao longo desses nove anos de atividades ininterruptas.

Quando estava começando minha aproximação junto ao grupo em 2018, participei de um encontro que desvelaram depoimentos que revelam histórias de superação, e que marcam o início dos trabalhos no Entre Elas. Relatos como o de Adeguimar de Jesus, que chegou a ser desacreditada pelos médicos que disseram que ela poderia morrer, ou vegetar em cima da cama após realizar a cirurgia de retirada de um meningioma (um tumor geralmente benigno em uma das membranas que envolve o cérebro), mas ela decidiu que iria lutar pela sua vida. Relata que, após a cirurgia, percebendo que estava inteira, decidiu lutar para conseguir movimentar o corpo novamente. Em sua jornada para recuperação, fez tratamento com fisioterapeuta, psicólogo e foi encaminhada para o CRAS, quando encontrou com Nil César propondo a oficina de teatro. Tendo chegado utilizando cadeira de rodas, foi aos poucos conseguindo se levantar, deu um passo, depois outro e afirma que o teatro ajudou demais em sua recuperação e a alcançar seu objetivo que sempre foi o de lutar para viver e se recuperar.

As pessoas e suas histórias são quem fomentam esse espaço de experimentação, ressignificação, reconstrução e movimentação humana e artística. Com o tempo, trabalhando na "confluência entre o espaço da sociabilidade (formação do cidadão) e o espaço da representação" (VENANCIO, 2008, p. 37),

9 Peça montada em 2003, a partir de entrevistas realizadas com vinte mulheres da comunidade, as quais narraram suas vidas marcadas pela violência e também por lutas por melhores condições de vida. 
buscando explorar mais técnicas do fazer artístico, histórias de vida, como essa destacada acima, foi entrelaçada com as memórias da comunidade, tornando-se material de improvisações constantes.

O Grupo possui dois espetáculos em repertório: Quando eu vim para um Belo Horizonte (2014) com direção de Nil César e Fernanda Carvalho, tendo este sido remontado em 2019, e Mãe, Raiz do Morro, com direção e dramaturgia de Liliane Alves, Marcelo Oliveira e Fernanda Carvalho.

Mãe, Raiz do Morro é resultado de um processo de pesquisa a partir do questionamento "o que é ser mãe? O que é ser mãe do morro e mãe do asfalto?" (Fazendo um contraponto entre a favela e os espaços privilegiados socialmente). O espetáculo estreado em 2016 é assim revelado por sua sinopse:

Como se equilibrar entre o mito da mãe ideal e os desafios de educar seus filhos dentro de um espaço tão emblemático como a favela? Ser mãe no morro é diferente de ser mãe fora dele? Foi buscando responder questões como essas que as atrizes de "O Teatro Entre Elas" - mães e moradoras de favelas - entregaram-se a um processo de trabalho com as memórias pessoais, pesquisa, registro de relatos de outras mães e moradoras de comunidades, para construírem a montagem “Mãe, Raiz do Morro". O que se busca com essa peça é revelar a face materna das mulheres que, transitando as vielas do morro, embalaram em seus braços sonhos, trabalhos e desejos de um destino melhor.

Durante o período que estive em contato com o Grupo, tive a oportunidade de criar artisticamente junto a elas, idealizando com Liliane, a cena curta A Rede que foi apresentada na Mostra da Casa do Beco no ano de 2018. Em 2019, foi realizada a remontagem da peça Quando eu vim para um Belo Horizonte, integrando as mulheres advindas da oficina O Afeto na melhor idade ao elenco desta. Momento em que tive a surpresa e o prazer em ser convidada para fazer assistência de direção da peça, sendo que esta versão teve estreia em maio do mesmo ano.

O processo foi pautado por uma reconstrução do roteiro feito por Nil César e Liliane Alves, que agora assumia também a 
direção desse espetáculo. A partir do roteiro já construído eles iam estruturando em improvisos, junto com o grupo, as novas cenas.

Nesta versão do espetáculo, as quinze mulheres se revezam em cena entre cinco personagens guias, perpassando infância, adolescência e vida adulta destas. Elas se revezam ainda entre outras personagens tais como: adolescentes convidadas da festa e como próprias moradoras do Morro do Papagaio. A nova versão é assim apresentada por sua sinopse:

Quinze mulheres se revezam no palco, a fim de darem vida a cinco personagens: Cotinha, Gertrudes, Mariana, Amélia e Jussara. A narrativa permeia a trajetória dessas personagens, desde a infância das brincadeiras e do trabalho a adolescência, construída a partir de sonhos de uma vida feliz no casamento. Em meio à trama das personagens, o público depara com as memórias das experiências reais das atrizes, que contribuíram para a dramaturgia, ao darem seus depoimentos de vida. Assim, entre sonho e realidade, acompanhamos a saga de Cotinha, descobrindo a mesma trajetória comum a milhares de mulheres que migraram para as capitais brasileiras, a fim de escaparem de uma realidade opressora - seja a de seus maridos violentos, seja a dos poderes oligárquicos ainda presentes nos grotões do país. Cotinha escoIhe instalar-se, com os filhos, no Morro do Papagaio, em Belo Horizonte, na esperança de uma vida menos sofrida do que a vivida no passado, deixando-nos como mensagem a coragem de se recriar e de sempre recomeçar, pois "Pior do que está, não pode ficar".

O roteiro inicia com uma cena em que são feitas brincadeiras de roda junto com o público, tal como um prólogo. Seguidamente, as "crianças" vão para área de cena e acontece a cena da infância: brincadeira com bonecas, morte e enterro das bonecas, trabalho infantil e uma criança que não trabalha que é Mariana, a filha do patrão que humilha as outras. Há um revezamento de atrizes porque agora a adolescência será abordada por meio do trabalho, dos sonhos e do desejo de arrumar um 
namorado/marido. Segue então para o baile de 15 anos de Mariana, em que algumas precisam trabalhar na festa.

O baile é divertido e pessoas do público são convidadas a dançar com as atrizes. Apenas uma, a Cotinha, não havia conseguido um par, entretanto ela narra como encontrou seu primeiro marido. Há uma quebra em que algumas mulheres narram suas experiências de vida com o casamento. É o momento em que Júnia, Maurina, Milta, Maria das Graças, Cruzelina, Paula e Du Carmo contam como conheceram seus maridos: são revelados anos de vida sofrida, violência doméstica, morte de companheiros, separação, mas também anos de companheirismo, a alegria de ter filhos e uma família e de hoje algumas já serem até bisavós. São narrativas próprias em que elas, estando imersas e amparadas pelo fazer artístico, falam verdadeiramente e sem tabus de suas vidas áridas.

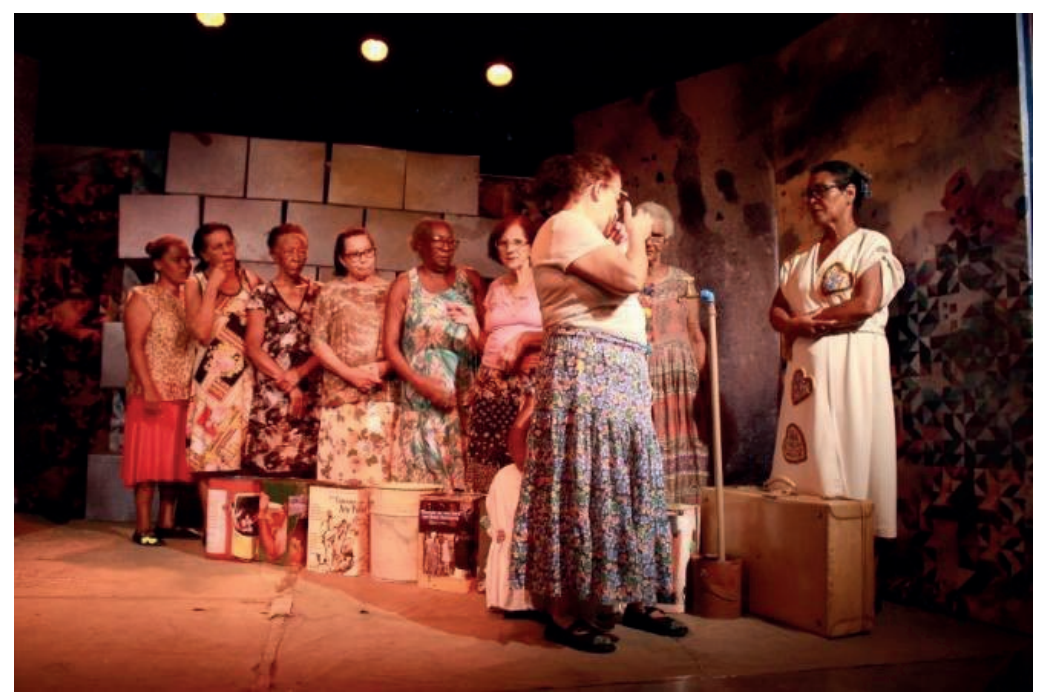

Figura 1: Cena da lata d'água na peça Quando eu vim para um Belo Horizonte (2019)

Fonte: D'Alessandro, Carol. Belo Horizonte (2019). 
Após os depoimentos, os revezamentos das atrizes tornam-se mais frequentes entre diferentes personagens. Segue-se focando na história de Cotinha que casa, o marido é alcoólatra e bate nela, ela decidi se separar e ir com seus três filhos para morar em Belo Horizonte, na oportunidade em que o Papa visita a cidade. Chegando a $\mathrm{BH}$, ela se instala no Morro do Papagaio. O local começa a ser evidenciado na cena da lata d'água, em que elas formam uma fila de madrugada para pegar água em uma torneira que só disponibiliza água em poucas horas do dia.

Aqui é inserida a cena de uma tentativa de assalto. É o jovem da favela que começa no crime, como relata Nil César:

\begin{abstract}
A gente criou um bandido que entrou no crime há pouco tempo, e que a dona de casa na rua coloca a mão no rosto do menino e fala: eu conheço sua mãe. Cê tá novo. Cê entrou agora, dá tempo de sair. Ele deixa a arma cair, ela entrega a arma, ele é desastrado, ele é humano também, né? É...e aí ele fala: vaza daqui. E ela fala: vaza você, eu vim pegar água. Eu tenho o que fazer. Ah tá, então tá, vazo eu. Não que eu esteja, que a gente nessa construção esteja amenizando a violência, a criminalidade, mas em algum momento essas crianças começam, né? E são crianças que se não foi essa dona que viu o menino nascer, e que conhece a mãe, é filho de alguém. Já foi criança. Já teve um sonho. Que por algum momento, por algum motivo, ou por alguma ausência, deixou de sonhar. E tentou buscar uma forma mais rápida, eu não digo fácil porque eu não acho, não acredito que traficar, entrar na criminalidade, trocar tiro, correr de polícia seja fácil. Mas mais rápida de, de conquistar o sonho, né? (Nil, 10/06/2019) ${ }^{10}$.
\end{abstract}

Havia uma preocupação em humanizar esse bandido que ainda era um jovem inseguro, e de problematizar a inserção na criminalidade em um espaço também marcado por múltiplas vulnerabilidades sociais e falta de oportunidades e perspectivas.

10 Os fragmentos de entrevistas transcritos neste artigo serão feitos em itálico, constando entre parênteses o primeiro nome do entrevistado e data em que a entrevista foi realizada. 
Na sequência, a Cotinha se instala no morro e tem ajuda de várias pessoas para construir seu barraco. É enfatizada aqui a solidariedade inerente àquela comunidade. Susete lembrava a todo tempo durante os ensaios que aquilo aconteceu com ela, que ela foi muito ajudada, cada um colaborando com o que podia, seja uma madeira, um móvel que não usava mais. Nessa cena, um amontoado de caixas que a todo tempo ficava no fundo de cena e de onde eram também retirados elementos cênicos, é desfeito simbolicamente como a construção da casa e revela-se uma plotagem com a vista do morro. Trata-se de uma montagem de várias épocas diferentes. Adeguimar, logo quando viu a imagem pela primeira vez, disse que a vista que ela tem de sua casa é bem parecida com aquela. É a vista da janela de Cotinha, que agradece a ajuda de todos e já sozinha em cena olha para a mesma, suspira por ter chegado até ali e a peça acaba.

Tendo estreado e feito temporada na Casa do Beco, o espetáculo também circulou por praças da cidade de Belo Horizonte/ MG, Betim/MG e Contagem/MG cumprindo agenda do Circuito Unimed $\mathrm{BH}^{11}$.

O trabalho de divulgação da Casa do Beco, sob o comando de Carol D'Alessandro, buscou nessa oportunidade, dar uma maior visibilidade para o trabalho e a existência do Grupo Teatro Entre Elas. Nesse percurso, elas gravaram programas como o Globo Horizonte ${ }^{12}$, Gerações ${ }^{13}$, Sou $60+{ }^{14}$ e realizaram entrevis-

11 Em 2019, a Casa do Beco recebeu o patrocínio do Instituto Unimed BH via lei de incentivo federal; da CEMIG via Lei Estadual de Incentivo à Cultura e da MGS via Lei Municipal de Incentivo à Cultura.

12 Globo Horizonte apresentado por Renata do Carmo foi ao ar dia 16/06/2019. Disponível em: https://globoplay.globo.com/v/7693769/ (Último acesso em jan. 2020).

13 Programa Gerações Casa do Beco disponível em https://www.youtube.com/ watch?v=EHEm6JRi1do.

14 Programa dentro da série "Sem Constrangimento" com o título: Sempre é possível mudar e melhorar a vida, inclusive na velhice!, veiculado pela Rede Minas e no canal do youtube Sou 60 por Roberta Zampetti. Disponível em https:// www.youtube.com/watch?v=qGx34Fe29Ls. (Último acesso em jan. 2020). 
tas para o portal G1, o jornal Folha de São Paulo, entre outros. Era notável a emoção delas em participarem dos programas, mas também se percebia um desprendimento, uma abertura e um desejo de falar delas e do teatro. Há sempre interesse por parte dos jornalistas em saber das histórias de vida e penso que este seja um movimento muito significativo para elas, para além de poderem se expressar no teatro, terem também um espaço midiático para tal, pois como bem lembra Nil "elas viveram uma existência de invisibilidade, foram invisíveis a vida inteira" e agora têm espaço para falaram de si.

Nesse percurso eu presenciei vozes e histórias, que antes não eram ouvidas ou eram silenciadas, sendo evidenciadas, tanto no teatro quanto na mídia. Mulheres comuns, moradoras do morro, tendo a oportunidade de falarem de si, de se tornarem corpos vistos, rompendo com um sistema que comumente marginaliza e invisibiliza tais pessoas e discursos. Dessa maneira, as lentes teóricas utilizadas para enxergar esse campo de estudo, se apoiaram na feitura de um Teatro em Comunidades, e na configuração deste fazer como uma partilha do sensível, conforme abordarei a seguir.

\section{TEATRO ENTRE ELAS: O TEATRO EM COMU- NIDADE COMO PARTILHA DO SENSÍVEL}

A autora Marcia Pompeo Nogueira ${ }^{15}$ fomentou a discussão sobre o Teatro em Comunidades no Brasil, bebendo nas fontes teóricas principalmente do teatro comunitário inglês, para refletir sobre as práticas nacionais. Para se pensar a dimensão do trabalho realizado na Casa do Beco, especificamente com o Grupo Teatro Entre Elas, nesse heterogêneo campo, tracei como ponto de partida os entendimentos comuns explicitados nessas práticas por Nogueira:

15 Marcia Pompeo Nogueira foi professora da Universidade do Estado de Santa Catarina (UDESC), pesquisadora de temas como Teatro em Comunidades e Teatro para o desenvolvimento. 
Trata-se de um teatro criado coletivamente, através da colaboração entre artistas e comunidades específicas. Os processos criativos têm sua origem e seu destino voltados para realidades vividas em comunidades de local ou de interesse. De um modo geral, mesmo usando terminologias diferentes, esboça-se um método baseado em histórias pessoais e locais, desenvolvidas a partir de improvisação. Cada terminologia, a seu modo, guarda relações com um processo educativo entendido ou não como transformador. Do meu ponto de vista podemos, no Brasil, chamar essas práticas de Teatro em Comunidades. (2008, p. 4-5).

De imediato, reconheço princípios no trabalho desenvolvido no Entre Elas: o teatro criado com elas e entre elas respeita os desejos apontados pelas mulheres; é criado coletivamente; a realidade vivida individual e comunitariamente é a matéria prima do processo de criação, sendo a improvisação o método privilegiado do trabalho criativo. Do ponto de vista educativo, é entendido como transformador, uma vez que o trabalho voltado para a transformação social é objetivo central nesse espaço de fazer artístico.

Para se pensar tais práticas há sempre uma discussão em torno do conceito de comunidade. Entretanto, ao longo de suas reflexões acerca do tema, Nogueira e outros estudiosos do campo no Brasil, se apoiaram na definição proposta pelo autor inglês Baz Kershaw, que identifica as comunidades de local e as comunidades de interesse. As comunidades de local são criadas por uma rede de relacionamentos formados por interações face a face, numa área delimitada, já as comunidades de interesse são formadas por uma rede de associações, caracterizadas por um comprometimento em interesses que são comuns, não necessitando estarem delimitadas por uma mesma área geográfica.

O Grupo Teatro Entre Elas abrange em sua base uma comunidade de local e se mantém aberto às comunidades de interesse. Ao mesmo tempo em que se fixa no Morro do Papagaio, e a maioria de suas integrantes são moradoras locais, recebe três mulheres de outras periferias da cidade e uma de outro estrato social, que se reconhecem nessa comunidade de mulheres e no desejo do fazer teatral. 
Mergulhando no campo teórico para buscar entender os contornos da teoria à qual me filio, encontro o livro Teatro na Comunidade: interações, dilemas e possibilidades (2009), organizado pela autora Marcia Pompeo Nogueira. O livro aborda as discussões levantadas em torno de práticas de teatro em comunidades, partindo da hipótese de esta ser umas das modalidades teatrais mais praticadas no Brasil, embora pouco refletida academicamente, até então. Atualmente, tais reflexões encontram-se em pleno desenvolvimento.

O livro Teatro e Dança como experiência comunitária (2009), organizado por Victor Hugo Pereira, Zeca Ligiéro e Narciso Telles, traz uma contribuição muito significativa revelando os diferentes pontos de vistas e a amplitude do campo do teatro em comunidades. Na obra, é possível conhecer experiências como de teatro na prisão com detentos da penitenciária Lemos Brito/ $\mathrm{RJ}$; o processo de criação utilizando o Teatro do Oprimido do Coletivo Estadual de Negros Universitários/RJ; teatro com idosos como a experiência de Beatriz Venancio em sua oficina de Teatro e Memória, entre outros.

Esmiuçando as produções que abordam o campo, é notável a atuação do grupo Nós do Morro no Rio de Janeiro, sendo este um importante trabalho de teatro em comunidades no Brasil, que vem sendo pesquisado e teorizado, referência encontrada sempre que há uma reflexão sobre o tema. A autora Marina Henriques Coutinho ${ }^{16}$ fez um estudo aprofundado do grupo, fundado em 1986 em movimento dialógico entre artistas do morro e artistas externos à cultura da favela. Ideia que ganhou contornos que conquistou a comunidade, transformando-se em movimento próprio da comunidade/favela, passando a ser produzido por ela e para ela, sendo uma manifestação legítima dos seus moradores.

16 Marina Henriques Coutinho é Professora do Departamento de Ensino do Teatro, do Programa de Pós-Graduação em Ensino das Artes Cênicas (PPGEAC) e do Programa de Pós-Graduação em Artes Cênicas (PPGAC) da Universidade Federal do Estado do Rio de Janeiro (UNIRIO) onde coordena entre outros projetos o Programa Teatro em Comunidades. 
Ao voltar o olhar para a cena belo-horizontina, encontrei a pesquisadora Renata Patrícia da Silva (2012), que refletiu em sua dissertação sobre a experiência desenvolvida pela Cia Zona de Arte da Periferia, conhecida como ZAP 18, salientando aproximações dos trabalhos desenvolvidos dentro do campo teatro em comunidades. A autora evidencia traços desse campo na inserção e estratégia de aproximação dos artistas com a comunidade do bairro Serrano. As propostas de oficinas pedagógicas, por vezes, trabalham com temáticas oriundas dos desejos dos alunos/moradores e da relação dialógica estabelecida também nos processos criativos do grupo, em montagens de espetáculos que buscam abordar as realidades vividas na comunidade.

Por ser um campo muito vasto, as discussões terminológicas reverberam o uso de preposições que buscam delinear características dessas práticas. Três modelos são explicitados: O teatro para comunidade que é aquele feito por um grupo de artistas para se apresentar na comunidade sem conhecer a sua realidade, tal como um teatro de mensagem; o teatro com comunidade feito por um grupo de artistas respeitando às necessidades das pessoas, fazendo parte do processo de criação a escuta da comunidade, inspirado nas abordagens de Augusto Boal em o Teatro do Oprimido (2010) e de Paulo Freire e a Pedagogia do Oprimido (2005); e o teatro por comunidade que é aquele feito pela comunidade contando as suas histórias, é um processo que dá ao povo os meios de produção teatral, consolidando as ideias de Boal e Freire, e "ele seria, neste sentido, porta-voz de assuntos locais, o que poderia contribuir para expressão de vozes silenciosas ou silenciadas" (NOGUEIRA, 2017, p. 18).

O labirinto de terminologias aponta ainda versões no Brasil para teatro de comunidade; teatro $e$; teatro $n a$; teatro em; teatro comunidade; e, ainda, teatro pela comunidade.

Percebendo as complexidades terminológicas, e que as reflexões sobre o tema encontram-se em desenvolvimento, opto por adotar o termo Teatro em Comunidades a partir do ponto de vista da pesquisadora Marcia Pompeo Nogueira, uma vez que este já advém de uma reflexão sobre práticas brasileiras, tem sido o mais aceito e utilizado atualmente e por entender o 
termo em indicativo de relação de lugar, como aquilo que está dentro, que pertence a. O teatro desenvolvido na Casa do Beco reflete uma história que emerge de moradores da comunidade e que é disseminada por ela e dentro dela, explicitando seu total pertencimento às suas práticas.

Compreendo que um trabalho realizado para a comunidade, sem levar em conta a realidade local, apresenta uma oposição conceitual em seu fazer muito significativa em relação ao teatro feito em/por/pela comunidade. No primeiro a comunidade é entendida como recebedora, no segundo é entendida como geradora. Todavia, Nogueira mapeia práticas que acontecem em contextos comunitários, penso que reside aí o ponto de encontro, mesmo que elas apresentem contradições entre si. Por hora, é nesse ponto que apoiamos a discussão, mesmo que estejamos cientes de toda gama de incertezas e questionamentos que lhe são atravessadas.

Entretanto, percebo que se apresentam neste emaranhado conceitual, duas vertentes que se separam em pontos cruciais, relativos à sua práxis. Uma vertente que forja um trabalho de cima para baixo, quer dizer que mantém as ideias dominantes e, nesse sentido, se opõe à prática dialógica inspirada em Freire. Estão contidos aqueles contextos em que uma instituição pensa um trabalho a ser inserido em determinada comunidade, um grupo de artistas que prepara apresentações com mensagens entendidas por eles como importantes, que retratam o cotidiano comunitário a partir do ponto de vista externo, ou até como ensinamentos para os outros. E outra vertente que se constrói em diálogo entre artistas externos e a comunidade local, ou com as próprias comunidades sendo protagonistas de seus projetos, que utilizam das histórias pessoais e locais em seus processos criativos e que pode ser entendido como transformadora para quem vive essa experiência. Percebo que as marcas do campo, conforme delineadas por Nogueira (2008) estão fortemente contidas nessa segunda vertente apresentada, e é nela que situo o trabalho da Casa do Beco com o Grupo Teatro Entre Elas.

O trabalho no Entre Elas é delineado a partir de improvisações que evidenciam as histórias pessoais e locais. Cada nar- 
rativa perpassava as experiências de vida das mulheres que, muitas vezes, nunca tiveram a oportunidade de serem ouvidas. Minúcias, detalhes, pequenas mudanças, oportunidade de ser, instaurando o teatro como sendo o espaço encontrado para "alguma coisa que eu fizesse pra que eu voltasse a ter vontade de continuar vivendo". Representa a chance de falar das desigualdades vividas e vistas tendo o "teatro como incentivo para chegar até essas condições de eu poder falar sobre isso e as pessoas me ouvirem e entenderem o meu lado, como mãe que mora numa favela [...] essa é a chance e eu vou à luta", como expresso por Adeguimar de Jesus.

O percurso do grupo é marcado pelos desejos das integrantes de se expressarem através do teatro, de contar as suas histórias e a de outras moradoras do morro, de tomarem a palavra: "Tomar a palavra, como parte deste processo de subjetivação política, não significa ocupar um espaço discursivo já existente, mas escavar e conformar este próprio espaço ao mesmo tempo em que nele se instala" (PALLAMIN, 2010, p. 10).

Libânio destaca que:

Ao longo da história, foi através de suas manifestações artísticas, endêmicas ou importadas, que a favela teve algum tipo de reconhecimento e aceitação. Primeiro, pelo samba e o carnaval; depois, pelo rap e pelo funk. Hoje, por sua multiplicidade e diversidade cultural, é por intermédio da arte que o morador de favela encontra seu lugar e seu valor nas representações sociais. (2008, p. 33).

Nesse sentido, é no teatro que essas mulheres têm encontrado seu valor e lugar nas representações sociais, reconhecendo e descobrindo suas potencialidades, compartilhando e resignificando suas histórias de vida e de sua comunidade. Integrando o Teatro Entre Elas, elas têm a oportunidade de se reconhecer enquanto seres falantes, cuja opinião tem importância e história tem valor, podendo até virar roteiro de teatro.

Foi então nesse lugar - o espaço em que vozes, corpos, falas, histórias, que até então não eram consideradas, aparecem e 
são percebidas, fazendo emergir como tomam sua parte e tornam-se parte perceptível neste comum -, que pude aproximar os contornos políticos que atravessam esse fazer artístico em encontro profícuo com os pensamentos do filósofo Jacques Rancière, que apresenta, em uma vasta e complexa obra publicada, o seu pensamento de uma filosofia política.

Em linhas gerais, o autor propõe chamarmos de polícia aquilo que até então era entendido como política e restringe este último conceito. A organização dos poderes, o processo de hierarquização que organiza cargos e funções, o que determina a ordem social é chamado pelo filósofo de polícia, entendimento que é contrário à política. A polícia congrega as hierarquias, organiza lugares, exclui uns e outros e é da ordem do consenso. O consenso é certo regime do sensível em que as "partes" já estão dadas a priori, a comunidade já está constituída e já está definido quem tem direito à palavra, pressupondo assim o desaparecimento de toda distância entre a "partes"17 de um litígio e a "parte" da sociedade, em suma, o desaparecimento da política (RANCIÈRE, 2018).

A política, por sua vez, seria um acontecimento, algo incomum, uma raridade, e estaria instaurada em processos de luta, de conflitos, quando a palavra é tomada pelos que não têm parte, ela é "aquela atividade que rompe a configuração sensível em que as "partes" e as partes ou sua ausência são definidas com base em um pressuposto que, por definição não tem lugar: a de uma parte dos que não tem parte" (RANCIÈRE, 2018, p. 43).

A atividade política então faz ver aquilo que não era visto,

170 autor explora ao longo do livro as múltiplas implicações entre part (parte enquanto pedaço ou fração de um todo) e partie (parte enquanto sujeito socialmente reconhecido, como se diz, por exemplo, de um contrato assinado por várias "partes"). Como os dois termos em francês encontram sua correspondência mais direta no português na palavra parte, e esta guarda corretamente as duas acepções, esta edição optou - com a concordância do autor - por não recorrer a um terceiro termo (como parcela ou quinhão para verter part). Com o intuito de preservar as relações presentes no texto original, part será vertido sempre como parte, e partie, como parte entre aspas: "parte". (Nota de rodapé, O desentendimento, 2018, p. 17). 
faz emergir discursos antes só ouvidos como ruídos. "A política ocorre quando a lógica promovida pelas partilhas desigualitárias ou a ordem da dominação que é tida como natural, são perfuradas por lutas e conflitos empenhados na atualização do princípio da igualdade" (PALLAMIN, 2010, p. 8).

O conceito "partilha do sensível", define a existência de um comum que é dividido em partes respectivas. Dessa forma, o autor aponta que temos um comum que é partilhado e ao mesmo tempo dividido em partes exclusivas. Funda-se uma partilha de tempo, espaços e tipos de atividades que estabelece como um comum é partilhado e como uns e outros tomam parte nessa partilha. O filósofo nos coloca ainda que um mundo comum "é sempre uma distribuição polêmica das maneiras de ser e das "ocupações" num espaço de possíveis" (RANCIÈRE, 2009, p. 63).

Percebe-se que o conceito fala de desigualdades, de corpos que são visíveis ou invisíveis, de vozes que são ouvidas ou silenciadas, dos espaços que cada um ocupa nesse comum. No Teatro Entre Elas, emergem corpos e vozes como a de Du Carmo, que afirma que, antes de fazer teatro, pensava que as pessoas não dariam importância para o que ela tinha a dizer, e que hoje se sente emocionada, pois não imaginava que poderia ter "esses encontros com outras pessoas". Foi no fazer teatral que ela se reconheceu como ser falante, tendo a oportunidade de falar de si e de contar a sua história.

Com o princípio de que as práticas artísticas são formas que intervêm nas maneiras de fazer, de ser e de dar visibilidade a um povo (RANCIÈRE, 2009), quando o trabalho de teatro em comunidade realiza espetáculos que colocam em cena as histórias pessoais, que se fundem com as histórias coletivas, as pessoas da comunidade se reconhecem dentro de algo que é partilhado por um coletivo.

Dessa maneira, a participação e atuação no Grupo Teatro Entre Elas colocam em evidência a vida e história das suas integrantes. Reverbera um espaço em que aquelas mulheres podem se expressar, interagir e construir outros modos de existência. Aproximar a existência desse trabalho a uma reconfiguração do sensível diz de corpos, vozes e fatos, que antes só eram tidos 
como ruídos e passam a ser ouvidos e percebidos por meio da cena teatral. A marca dialógica do teatro em comunidade, que busca enfatizar os anseios da comunidade, caminha no sentido de fazer emergir tais vozes e discursos. E nessa brecha, as pessoas encontram um espaço em que podem narrar suas histórias e em que se reconhecem na história do outro.

Nesse ponto, entendendo que a comunidade política é uma comunidade de experimentação, de tentativas, em que realidades não imaginadas ou percebidas passem a ser vistas, em que aqueles discursos percebidos apenas como ruídos passem a ser ouvidos, que é um espaço que reconfigura aquilo que é tido como "comum" em uma comunidade, compreendo que o trabalho realizado no referido grupo se configura em uma experiência de teatro em comunidade como partilha do sensível.

Liliane Alves, quando indagada sobre a relação da Casa do Beco com a comunidade, diz da importância desse espaço para a afirmação da identidade local, para elevação da autoestima daqueles moradores e de ser um espaço que porta a voz da comunidade para o resto da cidade, lembrando e afirmando sua existência, saindo de um anonimato próprio dos sem parte.

\begin{abstract}
[...] eu acho que a Casa do Beco é uma porta voz da comunidade nesse sentido de falar assim: "Nós existimos, né?" pro resto da cidade. Assim, essa invisibilidade que a gente vê, esse anonimato que a gente vê, eu acho que a Casa do Beco preenche esse lugar do anonimato e comunica, né, pra outros lugares, pra outras pessoas, é...uma qualidade de pensamento que existe aqui dentro das comunidades, uma qualidade artística que também existe dentro da comunidade. É... aí nesse sentido eu acho que tem sim uma afirmação da identidade daqueles que estão aqui. (Liliane, 24/06/2019).
\end{abstract}

Os espetáculos do Entre Elas não focam em sofrimento, pobreza, embora reflitam seus áridos cotidianos. Os espetáculos colocam em cena suas vidas, aspectos de suas infâncias, sonhos, acontecimentos reais, não como um peso, mas como mais uma história de vida como tantas outras, em um jogo musical, brincante, poético. É interessante notar que os públicos, 
independentemente de sua classe social, nos bate-papos após as apresentações, começam a falar das suas histórias também. Surgem depoimentos de vida e, de acordo com Nil César, "essas mulheres promovem isso assim, o desejo de falar de sua existência".

Para Nil, as integrantes do Entre Elas saem de uma situação de invisibilidade vivida até então e passam a ser vistas e ouvidas através do teatro. Dessa maneira, as agora atrizes passam a ocupar outro posto na partilha do sensível.

Ao colocar em evidência essas mulheres e suas histórias de vida, que são reconhecidas por outras mulheres em um espaço de escuta e visibilidade, o teatro em comunidade provoca uma reconfiguração dos olhares sobre o cotidiano da favela e de seus moradores. O estigma de que na favela há muita criminalidade, muita dor, muito sofrimento é contraposto a sonhos de vida, à alegria genuína de ser quem se é, de se relacionar com o outro. Dessa maneira, essas experiências particulares vão ganhando voz, e desafiam a visão hegemônica sobre o que é ser um morador de favela, propondo uma nova "partilha do sensível", e evidenciando uma prática de teatro em comunidade como partilha do sensível, em que o encontro comunitário é movido pelo diálogo, pela troca, sensibilidade e pelos afetos. 


\section{REFERÊNCIAS}

BARBIER, René. A pesquisa-ação. Tradução de LucieDidio. Brasília: Liber Livro Editora, 2007.

BOAL, Augusto. Teatro do oprimido e outras poéticas políticas. 10.ed. Rio de Janeiro: Civilização Brasileira, 2010.

FREIRE, Paulo. Pedagogia do oprimido. Rio de Janeiro: Paz e Terra, 2005.

LIBÂNIO, Clarice de Assis. Arte, Cultura e Transformação nas vilas e favelas: um olhar a partir do Grupo do Beco. 2008. Dissertação (Mestrado em Sociologia) - Faculdade de Filosofia e Ciências Humanas da Universidade Federal de Minas Gerais, Belo Horizonte. Disponível em https://pt.slideshare.net/ favelaeissoai/dissertao-grupo-do-beco. Acesso em: jul. 2017.

NOGUEIRA, Márcia Pompeo. Teatro em Comunidades: Questões de Terminologia. Anais do V Congresso da Associação Brasileira de Pesquisa e Pós-Graduação em Artes Cênicas, 2008. Disponível em https://www.publionline.iar.unicamp.br/index. php/abrace/article/view/1417/1530. Acesso em: jan. 2019.

NOGUEIRA, Márcia Pompeo. (Org). Teatro na Comunidade. Interações, poéticas e possibilidades. Anais do I Seminário Teatro e Comunidade: interações, dilemas e possibilidades. Florianópolis: Ed. Da UDESC, 2009.

PALLAMIN, Vera. Aspectos da relação entre o estético e o político em Jacques Rancière. Revista de Pesquisa em Arquitetura e Urbanismo Programa de Pós-graduação do Departamento de Arquitetura e Urbanismo EESC - USP. SP, 2010. Disponível em: https://www.revistas.usp.br/risco/article/view/44800. Acesso em: jun. 2017. 
PEREIRA, Victor Hugo; LIGIÉRO, Zeca; TELLES, Narciso (Orgs). Teatro e dança como experiência comunitária. Rio de Janeiro: EdUERJ, 2009.

RANCIÈRE, Jacques. A partilha do sensível: estética e política. 2.ed. Tradução de Mônica Costa Netto. São Paulo: Editora 34, 2009.

RANCIÈRE, Jacques. 0 desentendimento: política e filosofia. 2.e.d. Tradução de Ângela Leite Lopes. São Paulo: Editora 34, 2018.

SILVA, Renata Patrícia da. Teatro em Comunidades: o encontro entre os artistas da Cia ZAP 18 e a Comunidade do bairro Serrano e entorno, 2012. Dissertação (Mestrado em Artes) - Escola de Belas Artes da Universidade Federal de Minas Gerais, Belo Horizonte. Disponível em: http://www.bibliotecadigital.ufmg.br/ dspace/handle/1843/JSSS-967NH7. Acesso em: jan. 2019. VENANCIO, Beatriz Pinto. Pequenos espetáculos da memória: registro cênico-dramatúrgico de uma trupe de mulheres idosas. São Paulo: Aderaldo \& Rothschild, 2008. 